\author{
Barbu Adina
}

\title{
A case of acute leukaemia in a 38-years old female
}

"Ovidius" University of Constanta, Faculty of Medicine

\begin{abstract}
:
Leukaemia is cancer that starts in blood-forming tissues, such as bone marrow, and causes large numbers of abnormal blood cells to be produced and enter the bloodstream. The stem cells usually develop into a type of white blood cell called myeloblasts which do not mature into healthy white blood cells. The leukaemia cells are unable to do their usual work and can buil ${ }^{2}$ n in the blood and bone marrow so there is less spac healthy white blood cells, red blood cells and platel Anemia is a major sign but diagnosis is provided on microscopic examination of peripheral mear. Key words: myeloproliferation, $r$ roscopy, emia.
\end{abstract}

\section{Introducti ,}

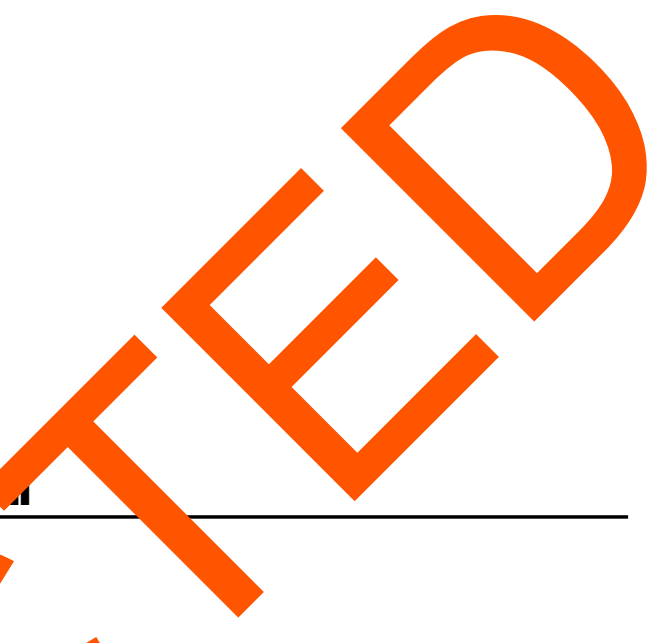

Adult acu myeloid leukaemia(AML) is a can $r$ of the blo $I$ and bone marrow. This cancer it is the of on type of acute leukaemia in adults. ML is arso called acute myelogenous leukemia, f. neloblastic leukaemia, acute granulocytic eukaemia and acute nonlymphocytic leukaemia.

\section{Gase report}

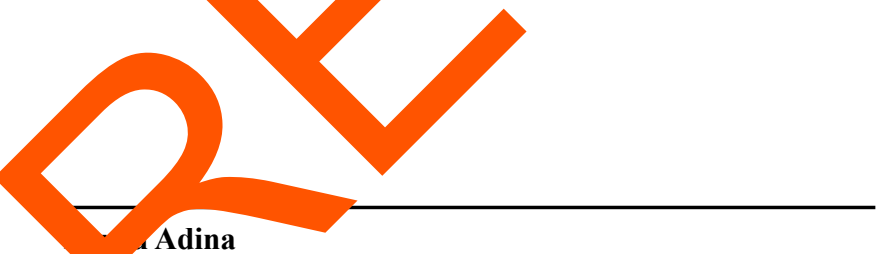

Adina

Univer Ovidius", Faculty of Medicine, Constanta

1, Aleea Universitatii

Tel/Fax: +40-241-605-004

e-mail: adina_barbu2004@yahoo.com
A young women, 38-years old, complained of severe fatigability and epigastralgy.

She presented in the emmergency of the hospital and the diagnosis was gastritis and it have been administered the antiacids. The laboratory tests indicated anemia $(9 \mathrm{~g} / \mathrm{dl}$.) but it was not realised microscopy of blood. Because the evolution was unfavorable and at the previous symptoms was added intense anal pain, she was examined by an internist and by an gynecologist for possible problems in the genital area. The diagnosis was not specified.The laboratory tests were restored and revealed: anemia, $\mathrm{RBS}=120 \mathrm{div} / 1 \mathrm{~h}$, increased bilirubin, increased transaminasis. 
Microscopic examination of peripheral blood smear revealed the presence of $90 \%$ blasts.

The pacient was admitted to the Department of Hematology and after chemotherapy treatment received a bone marrow transplant at Clinical Hospital Fundeni.(Figure 1)

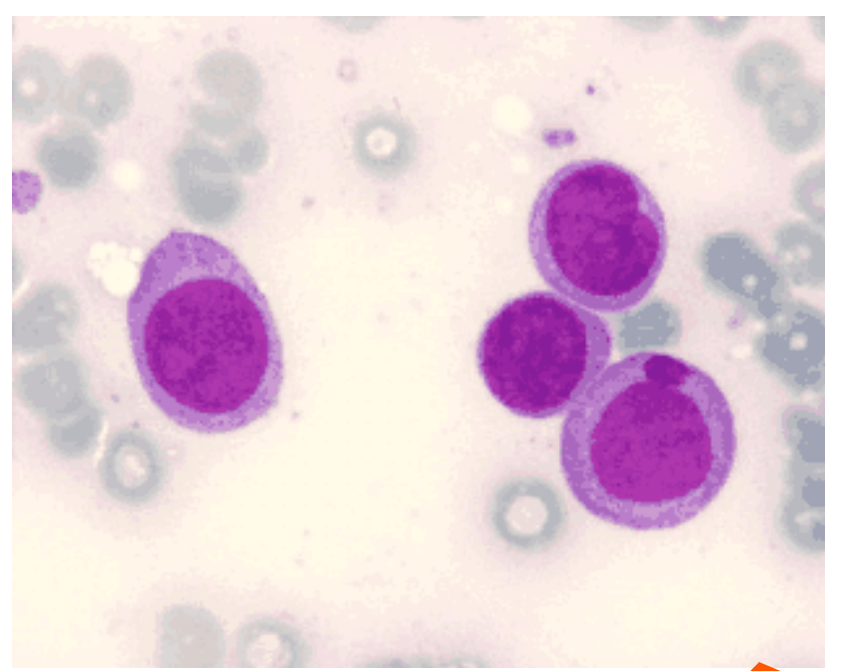

Fig.1- Peripheral blood smear

\section{Discussion}

The presented case is bout the possibility of misdiagno in acute myelo vliferation. Many haematolo anlisys levice show highnumber of white co in blo samples, and not enough red blood cells ots. Mar of the white blood cells m nyelo sts ("b" sts"), which are immature ood-fo ning ce are not normally found in the bloodst am. These immature cells do not function ike amal, ne white blood cells. These findings in suggest leukemia, but the disease usually is not diag ed without looking at a sample at microscope. ice 2003, when an international working group write recommendations for diagnosis in acute myeloid leukemia (AML), considerable progress has been made in elucidating the molecular pathogenesis of the disease that has resulted in the identification of new diagnostic and prognostic markers [2]. Immunophenotyping using multiparameter (commonly at least 3- to 4-color) flow cytometry is used to determine lineage involvement of a newly diagnosed acute leukemia, onven nal cytogenetics analysis is a mandato componen the diagnostic evaluation of a patie acute leukemia, chromosor abno alities ar detected in approximatel $55 \%$ of a $\mathrm{A}^{\mathrm{V}}$, methanol/acetic acid-f a cell hets sh be stored so if cytogenetio alys rails, fluorescence in situ hybridizat (FIS an opt to detect gene rearrange nts, but a bl sv is and a bone marrow asp ate part of the atine diagnostic work-up of a patien vith suspected AML. Blood and $p$ smears ar orphologically examined usi a May-Grünwald-Giumsa or a Wright-Giemsa st h. It is recom ended that at least 200 leukocytes or lood smears d 500 nucleated cells on marrow sme be counte with the latter containing spicules. For a of AML, a marrow or blood blast 'nt of $20 \%$ or more is required, except for AML (II 17), $\mathrm{t}(8 ; 21), \operatorname{inv}(16)$ or $\mathrm{t}(16 ; 16)$, and some cases of erythroleukemia. Myeloblasts, monoblasts, and megakaryoblasts are included in the blast count. In AML with monocytic or myelomonocytic differentiation, monoblasts and promonocytes, but not abnormal monocytes, are counted as blast equivalents. Erythroblasts are not counted as blasts except in the rare instance of pure erythroid leukemia.

\section{References}

1. William B. Clark, Stephen A. Strickland, A. John Barrett\& Bipin N. Savani(2010) - Extramedullary relapses after allogeneic stem cell transplantation for acute myeloid leukemia and myelodysplastic syndrome. Haematologica 95(6), 989. DOI:10.3324/haematol.2010.025890;

2. Hartmut Döhner, Elihu H. Estey, Sergio Amadori, Frederick R. Appelbaum, Thomas Büchner, Alan 
K. Burnett, Hervé Dombret, Pierre Fenaux, David Grimwade, Richard A. Larson, Francesco Lo-Coco, Tomoki Naoe, Dietger Niederwieser, Gert J. Ossenkoppele, Miguel A. Sanz, Jorge Sierra, Martin S. Tallman, Bob Löwenberg\& Clara D. Bloomfield(2010) -Diagnosis and management of acute myeloid leukemia in adults: recommendations from an international expert panel, on behalf of the European LeukemiaNet. Blood. vol. 115 no. 3 453-474;
3. R. Păun(1997) - Tratat de Medicină internă. Hematologie. Ed. Medicala Bucuresti;

4. Delia Mut Popescu (1997) - Hematologie clinica Note de curs. Editia a II-a.

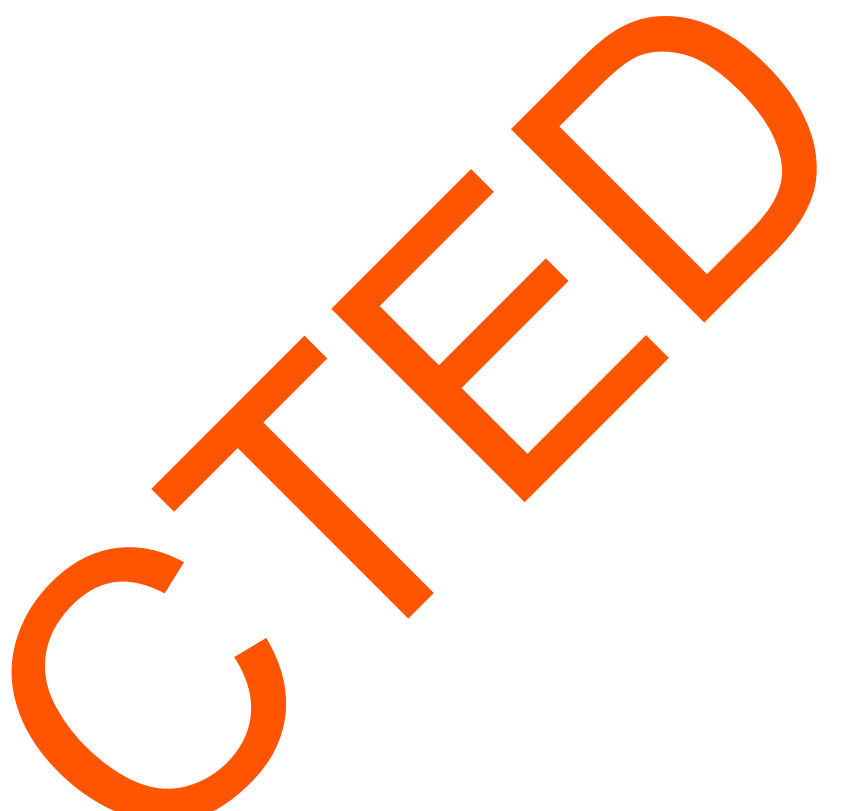

